\title{
The valuation and demand impacts of the worthwhile use of travel time with specific reference to the digital revolution and endogeneity
}

\author{
Mark Wardman $^{1}$ (D) Phani Chintakayala ${ }^{2} \cdot$ Chris Heywood ${ }^{3}$
}

Published online: 23 October 2019

(C) The Author(s) 2019

\begin{abstract}
The research reported here is concerned with how the worthwhile use of travel time might impact on the value of travel time savings (VTTS) and on demand set in the context of the rail travel market in Great Britain. It has long been recognised, in a variety of literature, that improvements in worthwhile activities which will have been delivered by the digital revolution will impact VTTS and demand yet there is surprisingly little reliable evidence and official appraisal practice does not accommodate any such effects. In a large survey of rail travellers, we have explored how activities while travelling impact on VTTS and demand. An important feature of the study was to account for endogeneity whereby variations in VTTS estimates according to the worthwhile use of time are biased if drawn from comparisons across individuals of what they do while travelling rather from comparing within individual variations in activities. Indeed, we clearly demonstrate the impact of not allowing for endogeneity and indicate its presence in other studies. We find that the VTTS does vary according to activities undertaken while travelling in a largely credible manner and is broadly consistent with behavioural responses to different available activities. The evidence supports the VTTS falling over time due to the digital revolution and rail demand increasing. These are modest rather than considerable changes but nonetheless contribute a better understanding of evidence relating to VTTS and rail demand variations over time.
\end{abstract}

Keywords Value of travel time savings $\cdot$ Worthwhile use of travel time $\cdot$ Rail demand forecasting $\cdot$ Digital impact on value of time $\cdot$ Multi-tasking and travel time $\cdot$ Intertemporal variations in value of time

Electronic supplementary material The online version of this article (https://doi.org/10.1007/s1111 6-019-10059-x) contains supplementary material, which is available to authorized users.

Mark Wardman

mwardman@outlook.com

Extended author information available on the last page of the article 


\section{Introduction}

There has been widespread acknowledgement that the ability to engage in worthwhile activities while travelling, sometimes referred to as multitasking, can be expected to reduce the disutility of travel time, and that the digital revolution will have provided a significant recent impetus. Nonetheless, there is very little reliable evidence on how the valuation of travel time savings for personal travel (VTTS) is impacted by being able to make worthwhile use of travel time.

The specific inspiration for this research was the strong and unexplained demand growth experienced by the rail industry in Great Britain from the mid-2000 s onwards. Leigh Fisher et al. (2016) ${ }^{1}$ demonstrate that rail demand can be forecast remarkably well between 1997 and 2004 but not over the period 2005 to 2011. Most notably, between 2007 and 2010 rail journeys grew by around $11 \%$ yet real GDP per capita fell by around $5 \%$ and the unemployment rate increased from around $5 \%$ to nearly $8 \% .^{2}$

Industry observers offered various explanations for this strong unexplained demand growth, such as improved reliability, investment in new trains, structural changes in the employment market, higher parking charges and reduced availability in major centres, and more effective marketing facilitated by advances in information technology. Whilst these would no doubt increase rail demand, only the marketing improvements would apply across the network. If though the VTTS for rail travel was falling, which corresponds to equivalent reductions in journey times, it might have appreciable demand effects across the network. And the VTTS might be falling in real terms because the advances in digital technology have supported a 'revolution' in how people spend their time on trains, from both a quantity and quality perspective ${ }^{3}$. Whilst the impact of the digital revolution on VTTS could make a significant contribution to explaining the unobserved growth in rail demand, there was no evidence that quantified the hypothesised effect. This was a primary stimulus to the research reported here.

We also drew inspiration from the track-record of research over many years into how the productive use of travel time might impact on the valuation of business travel time savings (VBTTS), a comprehensive account of which is provided by Wardman et al. (2015). And we recognised that whilst a research strand outside the mainstream economic approach to VTTS, with pioneering insights provided by the likes of Mokhtarian and Salomon (2001), Lyons and Urry (2005) and Kenyon and Lyons (2007), has focussed considerable attention on improved travel time use opportunities and their impacts on journey behaviour and satisfaction, the effect on VTTS has been acknowledged but not estimated. Finally, exactrepeat VTTS studies have speculated that the worthwhile use of time might be impacting on the inter-temporal variations estimated.

The research reported here contributes to the very limited evidence base on how worthwhile use of travel time impacts on VTTS and behaviour with specific reference to the

\footnotetext{
1 Using the rail industry's Passenger Demand Forecasting Handbook (PDFH) which contains an elasticity based forecasting framework and recommended parameters. The latest edition (v6.0) was released in May 2018 (Rail Delivery Group, 2018).

2 Indeed, we are aware of econometric studies of rail demand that covered these years which obtained negative elasticities to GDP per capita.

3 Whilst other modes might also be impacted, rail is best placed to benefit and hence this will induce mode switching. Moreover, there can be expected to be generation of new rail trips if travel time disutility is reduced.
} 
digital revolution. The issue is topical, as witnessed by a recent OECD Roundtable on the subject (ITF 2019), and is significant given the central importance of VTTS in transport planning, appraisal and forecasting. A specific and original feature of the research addresses the endogeneity induced by travellers planning worthwhile activities for their train journey. As pointed out by Wardman and Lyons (2016), those who dislike travel time will attempt to mitigate it with worthwhile activities while travelling, whilst those facing serious time pressures will be more likely to exploit travel time for useful purposes to release time elsewhere. That some with intrinsically larger VTTS are more likely to undertake more or higher quality worthwhile activities will lead to biased estimates of VTTS if, as is customary, the VTTS estimates are stratified across individuals according to on-train activities. We here overcome endogeneity by comparing within rather than across individual variations in VTTS according to activities undertaken while travelling.

This paper is structured as follows. "Background to VTTS and worthwhile use of travel time" section discusses important background matters, covering theoretical issues, official appraisal practice and previous relevant research, which leads into the need for the research reported here. The methods used, including a variety of different Stated Preference (SP) exercises, are set out in "Method" section. "Data collection and characteristics" section summarises the data collection process and the key features of the data collected. The survey findings are presented in "Survey findings" section with a synthesis of the evidence in "Synthesis of evidence" section. Concluding remarks are provided in "Concluding remarks" section.

\section{Background to VTTS and worthwhile use of travel time}

We here discuss the theoretical reasons underpinning the influence of worthwhile use of travel time on VTTS along with the extent to which it is accommodated in official appraisal practice. Of course, previous research provides important context, justification and motivation, and we set out our understanding of it.

\section{Theoretical considerations}

The theory of time allocation as set out by Bates (MVA et al. 1987), building upon DeSerpa (1971) and Bruzelius (1979), established the "fundamental property of time value" that the value of a time saving in activity $\mathrm{i}\left(\mathrm{VTS}_{\mathrm{i}}\right)$ is:

$$
\mathrm{VTS}_{\mathrm{i}}=\mathrm{RVT}-\mathrm{MVT}_{\mathrm{i}}
$$

RVT is the resource value of time, defined as the benefit of an increase in the total time budget if possible. Travel time has an opportunity cost and reductions in it mean that increased time can be allocated to activities as if there were an increase in the total time budget. $\mathrm{MVT}_{\mathrm{i}}$ is the marginal valuation of time spent in activity $\mathrm{i}$, which given we are here interested in VTTS reflects the disutility of travel time.

The $\mathrm{MVT}_{\mathrm{i}}$ term will be influenced by, amongst other things, the ability to undertake worthwhile activities whilst travelling. These can be expected to alleviate boredom and make the journey seem to pass quicker; some have argued they allow positive utility to be derived from travel time (Mokhtarian and Salomon 2001). Whilst public transport users have always been able to read, work and talk with companions during a journey, and these 
reduce the marginal disutility of travel time, the digital revolution takes this to a whole new level by extending appreciably both the quantity and the quality of possibilities.

Moreover, as a derived demand, travel time is often regarded as 'dead time'. If that travel time can be used to undertake activities that need to be done at other times, including work related activities, the released time is effectively an increase in available time. We would then expect those who have less dead time while travelling to have a lower willingness to pay to save travel time.

The conventional economic approach to VTTS can therefore accommodate worthwhile use of travel time. It is a separate matter whether official guidance does so.

\section{VTTS and appraisal practice}

Official appraisal guidance allows for variations in the VTTS according to the conditions of travel time. One of the oldest and most widely used conventions of transport planning (McIntosh and Quarmby 1970) is that walking and waiting time attract a premium, typically twice the value of in-vehicle time, whilst standing time and late arrival time are also assigned premium valuations in appraisal (Mackie et al. 2014). Where modal differences are permitted, they will in part be driven by variations in the marginal utility of travel time.

We are though unaware of official appraisal practice offering variations in recommended VTTS according to worthwhile use of travel time. This is perhaps unsurprising given that it has long been acknowledged that the productive use of time while travelling will impact on the VBTTS yet it is only in the Netherlands, Sweden and for a short time Norway where this has been incorporated within official guidance (Wardman et al. 2015).

\section{Previous research}

There are three areas of research which can inform how the VTTS might vary according to the worthwhile use of time:

- Inter-temporal variations in VTTS

- Cross-sectional variations in VTTS

- Behavioural Insights

\section{Inter-temporal evidence on VTTS variations}

We restrict consideration here to 'exact repeat' SP studies undertaken with the explicit purpose of investigating how VTTS varies over time and controlling for experimental design, data collection method, means of analysis, and socio-economic and trip related factors ${ }^{4}$ (Hague Consulting Group et al. 1999; Gunn 2001; Tapley et al. 2007; Börjesson et al. 2012; Significance et al. 2012).

These studies tend to find that the VTTS does not increase over time as might be expected. For example, in the first exact repeat study, involving the 1988 and 1997 Dutch national VTTS studies (Gunn 2001), the estimated VTTS were around 9\% lower in real

\footnotetext{
${ }^{4}$ So, for example, the SP design would be exactly the same except that the levels of cost variables would be adjusted to account for inflation.
} 
terms in 1997 after isolating other influences despite income growth of around 2\% per annum. This "non-helpful finding" was attributed to, "net systematic decreases in the disutility of travel time over time" and speculation that it stemmed from the advent of mobile technology in the period. Subsequently, Significance et al. (2012) covered the 1997 and 2010 Dutch national VTTS studies. Nominal values of time increased by $49 \%$ for commuting, $60 \%$ for business and $59 \%$ for other, yet inflation of $32 \%$ and real income growth of $30 \%$ might lead to larger increases. It was stated that, "VOTs could have been going down in the period 1997-2010 because it has become much easier to use travel time in all of the modes in a more productive and/or enjoyable way, since new technologies such as mobile phones (also hands free), laptops, iPads and smartphones with mobile internet have been introduced or become much more common in The Netherlands over this period".

Hague Consulting Group et al. (1999) reported on their repeat of an element of the first UK national VTTS study. The VTTS did not exhibit growth in real terms for either commuting or other trips despite $25 \%$ growth in real incomes per capita.

Whilst repeat studies provide some support for the hypothesis that VTTS might be falling, all else equal, due to increases in the quantity and quality of activities that can be undertaken while travelling, no quantification of these effects can be obtained from these studies.

\section{Cross-sectional evidence on VTTS variations}

Wardman and Lyons (2016) reviewed 14 national VTTS studies up to 2011 and concluded that "National studies do not have anything to say on how VTTS might be influenced by opportunities for worthwhile use of travel time". Since that review, there have been four further national studies and only in the recent UK study (Batley et al. 2019) has the issue been explored and then, possibly due to endogeneity, no significant variations in VTTS according to time use were discerned.

Kouwenhoven and de Jong (2018) have since reported further analysis of the Dutch 2010 national study. They found that train users who were able to spend their travel time usefully had, on average, VTTS $20 \%( \pm 5.5 \%)$ lower whilst for local public transport users the corresponding value was $21 \%( \pm 5.6 \%)$. As far as the availability of mobile phones, computers and music players was concerned, there was some evidence that this led to increased VTTS, contrary to expectations, and this was attributed to confounding effects including endogeneity.

The SP exercise conducted by Ettema and Verschuren (2008) found that, after controlling for socio-demographic and trip characteristics, those who listened to music had valuations around $70 \%$ lower, those who spent time reading for their work were in the range $36 \%$ to $53 \%$ larger and there was no significant effect for making phone calls. These estimated effects are not consistent, do not control for endogeneity ${ }^{5}$ and do not seem to modify the time coefficients by the amount of time spent in a specific activity.

Building upon the Malokin et al. (2017) RP mode choice models for commuting trips in Northern California, Etezady et al. (2019) specify the propensity to use a laptop/tablet as an interaction on the time coefficient, and this was found to reduce VTTS by the order of 20-30\%. However, the effect was specific to rail users and other factors, such as rail being more comfortable, could have been at work.

\footnotetext{
5 This is despite the SP exercise containing a variable denoting whether multitasking was available or not but which was not specified to interact with the time coefficient. Instead, the time coefficient was allowed to interact with whether the respondent read, listened to music or made phone calls.
} 
Table 1 Adjenughwure (2017) estimated VTTS (€/hr)

\begin{tabular}{|c|c|c|c|c|c|c|}
\hline & \multicolumn{3}{|l|}{ Commuting } & \multicolumn{3}{|l|}{ Leisure } \\
\hline & Reading & Working & Music & Reading & Working & Music \\
\hline $\begin{array}{l}\text { VTTS with preferred } \\
\text { activity }\end{array}$ & $11.22(18.7)$ & $12.72(12.3)$ & $10.08(10.9)$ & $4.11(12.1)$ & $6.54(9.6)$ & $5.95(8.9)$ \\
\hline $\begin{array}{l}\Delta \text { VTTS without pre- } \\
\text { ferred activity }\end{array}$ & $+4.82(4.6)$ & $+5.31(3.0)$ & $+4.67(2.3)$ & $+3.02(6.5)$ & $+1.17(1.1)$ & $+0.33(0.3)$ \\
\hline $\begin{array}{l}\% \text { Reduction due to } \\
\text { activity }\end{array}$ & $30.0 \%$ & $29.5 \%$ & $31.7 \%$ & $42.4 \%$ & $15.2 \%$ & $5.3 \%$ \\
\hline $\begin{array}{l}\text { Individuals/observa- } \\
\text { tions }\end{array}$ & $211 / 2532$ & $118 / 1416$ & $55 / 660$ & $352 / 4224$ & $28 / 336$ & $56 / 672$ \\
\hline
\end{tabular}

Varghese and Jang (2018) developed separate RP mode choice models in Mumbai for those who multitasked and those who did not. Whilst the former were found to have VTTS which were $26 \%$ lower, other confounding effects could have been at work, not least that the VTTS was a function of the journey cost which differed between the two groups. In addition, no allowance was made for the amount of time spent multitasking.

Yosritzal (2014) conducted an SP exercise of long distance rail travellers and found the VTTS to be highest for those engaging in electronic based activities, followed by non-electronic based activities with those not undertaking activities having the lowest values. Endogeneity could have contributed to this pattern of results whilst there was no allowance for the amount of time spent undertaking the activities in question.

Of some note is the study by Adjenughwure (2017) which adopts the Wardman and Lyons (2016) recommendation to allow for endogeneity by comparing within individual VTTS variations. ${ }^{6}$ Dutch train users were offered two SP exercises; one where they could continue with their preferred on-train activity and one where they could not. The results, from models pooled across the two exercises and allowing for scale differences, are reproduced in Table 1 . The significant incremental effects imply credible proportionate reductions in VTTS, in the range 30-42\%, whilst the insignificant effects could well stem from small sample sizes. Nonetheless, there are some limitations of the work. The preferred activity is deemed to be the activity that most time is spent on but there is no allowance for different activities or indeed the amount of time that is spent in the preferred activity or multitasking more generally. Moreover, it is not clear what is being valued, since the alternative to the absence of the preferred activity could be a close substitute or it could be no activity at all.

\section{Behavioural studies}

There is a large amount of empirical evidence relating to multitasking and activities undertaken whilst travelling emanating from an important strand of behavioural transport research outside of what might be regarded as mainstream VTTS research.

The largest category of evidence covers the activities individuals engage in while travelling and whether they consider their travel time to be useful, pleasant or wasted (Berliner

${ }^{6}$ Our research pre-dates this study and hence in our understanding is the first to control for endogeneity. 
et al. 2015; Gripsrud and Hjorthol 2012; Kenyon and Lyons 2007; Lyons et al. 2007, 2013, 2016; Russell et al. 2011; Tang et al. 2018; Van de Waerden et al. 2009; Yosritzal et al. 2017). There have also been many studies that investigate how worthwhile activities while travelling affect attitudes and journey satisfaction (Ettema et al. 2012; Frei et al. 2015; Mokhtarian et al. 2015; Rasouli and Timmermans 2014; van Hagen et al. 2017) and others that explore mode choice effects (Van der Waerden et al. 2010; Etezady et al. 2019; Malokin et al. 2017, 2019).

Whilst such studies tend to recognise that multitasking would be expected to reduce the VTTS, they do not seek to estimate how the worthwhile use of travel time impacts on VTTS. Indeed, Keseru and Macharis (2018) reviewed 58 studies covering travel-based multitasking and whilst there is recognition that multitasking will impact on VTTS, in addition to the other benefits it yields, there is no discussion of any quantification.

\section{The research need}

The evidence surrounding inter-temporal variations in VTTS, how multitasking influences usefulness of travel time and its effects on travel behaviour, journey satisfaction and mode choice, and theoretical reasoning surrounding the impact of the digital revolution, would each suggest that the VTTS has been impacted by significant increases in the quantity and quality of activities that can be engaged in while travelling. But none of these strands of research quantify the effect.

Whilst cross-sectional valuation studies have attempted to quantify how the VTTS varies with the worthwhile use of travel time, the evidence tends to have serious limitations. Variations in valuations are sometimes counter-intuitive, with a failure to allow for endogeneity a likely contributory factor, whilst in many cases it is not clear exactly what type of time is being valued.

What are required are multipliers to VTTS along the lines of the well-established practice for walk and wait time. Valuations must unambiguously relate to a specific activity and the minutes spent in that activity. Our view is that this requirement is not met in previous studies. This research aims to address these gaps and limitations.

\section{Method}

We here explain the reasoning behind and design of the three SP exercises offered to respondents along with the supplementary behavioural questions. ${ }^{7}$

\section{The stated preference exercises}

We designed three SP exercises which might be termed standard, strategic and tactical with the following purposes:

- SP1 This was a standard time- $\operatorname{cost}^{8}$ trade-off to estimate VTTS without any allowance for endogeneity.

\footnotetext{
7 The questionnaire used is available online as supplementary material.

8 Time throughout refers to train in-vehicle time.
} 
- SP2 This might be deemed a strategic SP exercise, providing a relatively straightforward means of determining the overall impact across travellers of not being able to use mobile devices or not being able to do anything, yet with the explicit feature of within rather than between individual comparisons to allow for endogeneity.

- SP3 This can be regarded to be a tactical SP exercise, offering clear and explicit amounts of time spent in specific activities and hence VTTS estimates for each of those activities again obtained from within rather than between individual comparisons.

The experimental designs were subject to simulation testing using synthetic choice data to ensure they could recover robust estimates of relative valuations across a wide but reasonable range.

\section{SP1}

This took the form common in many national VTTS studies of a simple trade-off between time and cost offered in the choice between two abstract alternatives. Each alternative was assigned just two levels of time, the current level and either an increase or a reduction, in order to facilitate asking what activities would be done (forgone) in the additional (saved) time. Separate time variations were specified for different journey lengths, covering plus or minus 15 min for journeys over $2 \mathrm{~h}$, plus or minus 10 min for journeys between 1 and $2 \mathrm{~h}$, and plus or minus $5 \mathrm{~min}$ for journeys between $20 \mathrm{~min}$ and $1 \mathrm{~h}$.

The variations in train times and fares were applied to respondents' reported current levels to ensure realism of absolute levels. Each respondent was offered 4 randomly selected choice scenarios from a set of 16 .

\section{SP2}

This exercise offered three options which differed in terms of what the respondent could do while travelling. They were simply characterised as:

- Option A Continue with current activities, whatever those might be;

- Option B Unable to use mobile technology devices;

- Option $C$ Unable to undertake any activities, other than look out of the train window or sleep.

The variations in train journey times differed according to the journey length and ensured Option $\mathrm{C}$ was quicker than Option B which in turn was quicker than Option A. Respondents were offered 4 choice situations randomly selected from a set of 16 .

\section{SP3}

This exercise presented two options, with one containing all the respondent's reference trip activities and the other removing the activity upon which most time was spent with its time re-allocated to the remaining activities but with train time reductions to compensate for the inferior set of activities. 
Table 2 Illustrative SP3 exercise (4 current activities)

\begin{tabular}{lllll}
\hline & Option A & \multicolumn{3}{l}{ Option B } \\
\hline Activity & Reading e-book & $20 \mathrm{~min}$ & & \\
& Internet browsing & $15 \mathrm{~min}$ & Internet browsing & $12 \mathrm{~min}$ \\
& Talking to others & $10 \mathrm{~min}$ & Talking to others & $8 \mathrm{~min}$ \\
& Do nothing & $10 \mathrm{~min}$ & Do nothing & $25 \mathrm{~min}$ \\
Train time & 55 min & & 45 min & \\
\hline
\end{tabular}

Given that this SP exercise presented an option which removed one activity, it requires that the respondent engaged in more than one activity. ${ }^{9}$ Mindful that an SP exercise based around all actual activities undertaken during a journey could be too complex, we limited the SP exercise to covering at most 6 reported activities from the set of specific activities listed in Table 4. In addition, activities that involved $10 \mathrm{~min}$ or less were ignored, and allocated to do nothing, on the grounds that there is limited scope for varying small amounts of time spent in specific activities. An attraction of this SP exercise is that it focusses respondents' attention on the activities whose impacts on VTTS we wish to estimate.

Table 2 provides an illustration. Option A is composed of four current activities, with the main one being reading an e-book. The latter is then removed from Option B with its time re-allocated to other activities. The times of each activity are then varied in order to allow their estimation whilst ensuring Option B is quicker given its inferior set of activities. Although we could have maintained the same four activities in both options and simply varied their times, we felt that removing an activity allowed us to realistically introduce greater variation in time spent in different activities. Whilst less straightforward than the other two SP exercises, the pilot survey did not raise any issues. Respondents were offered 4 choice situations randomly selected from a set of 16 .

\section{Behavioural questions}

Respondents were asked about their current activities while travelling, how much time was spent engaged in them and what they would do during the train journey in the absence of mobile devices. The opportunity was also taken to ask respondents about how multitasking opportunities impacted upon their rail travel behaviour. They were asked what they would do if they could not use their mobile devices, which is directly comparable with the SP2 exercise, and also whether any perceived improvements to engage in worthwhile activities while travelling had led to more train trips.

\section{Data collection and characteristics}

\section{Survey}

The requirement to offer sensible time-use scenarios based around actual activities undertaken while travelling, along with customisation of the times and fares offered to the reference journey, meant that a computerised presentation was essential.

${ }^{9}$ This includes doing nothing/looking out of the window. 
Table 3 In-vehicle time distribution for reference train journey

\begin{tabular}{lrl}
\hline & Commute & Other \\
\hline$\leq 1 \mathrm{~h}$ & $360(63 \%)$ & $744(52 \%)$ \\
$1-2 \mathrm{~h}$ & $130(23 \%)$ & $352(25 \%)$ \\
$>2 \mathrm{~h}$ & $81(14 \%)$ & $326(23 \%)$ \\
\hline
\end{tabular}

On-train computer based interviews would have been prohibitively expensive and so the pilot survey, undertaken in July 2014, involved on-train recruitment and invitation to an online survey. Whilst this did not identify any specific concerns with the survey questions and SP exercises, the response rate was too low to achieve the target sample of 2000 respondents within the available budget. We therefore opted for an online panel in the main fieldwork.

The main survey was undertaken in Autumn 2014 and yielded 1993 completed interviews. The focus of the interview was the last non-business rail journey of at least $20 \mathrm{~min}$ duration which, for recall purposes, had to have been made within the past month.

\section{Key features}

Table 3 reports the distribution of journey times ${ }^{10}$ for our sample of 571 whose reference trip was commuting and 1422 whose reference trip was other non-work related purposes. Commuters tend to be making shorter journeys, as might be expected, with the longer distance journeys being made by those who travel to remote work locations relatively infrequently.

The sample is closely balanced on gender, with $51 \%$ female, and displays a reasonable spread across different age groups with $22 \%$ between 16 and 24, 22\% between 25 and $34,16 \%$ between 35 and $44,24 \%$ between 45 and 59, and $16 \%$ aged 60 or over. Of the non-commuters, $53 \%$ were in full time employment or education, $16 \%$ were in part time employment or education, $18 \%$ were retired, $7 \%$ were not working, and $6 \%$ were looking after the family/home.

\section{Summary of multitasking behaviour and attitudes}

Around two-thirds of commuters and $44 \%$ of other travellers felt that at least some part of their reference train journey time was wasted. Of these, significant proportions of commuters $(42 \%)$ and other travellers $(44 \%)$ cited limitations in using their mobile devices as causes, although these issues will diminish over time, whilst train crowding was a factor for $27 \%$ of commuters and $17 \%$ of others. A separate question enquired as to whether crowding levels impacted on how travel time was spent. Overall, $7.9 \%$ of commuters reported some effect with $3.7 \%$ stating that they could do nothing. The equivalent figures for other trips were $5.1 \%$ and $2.3 \%$. Some digital devices, such as mobile phones, can be used even in very crowded conditions and indeed they may be particularly appreciated in such circumstances.

\footnotetext{
${ }^{10}$ Whilst the journey time is meant to relate to the time spent on the train, no doubt some respondents would have reported a door-to-door journey time.
} 
Table 4 On-train activities for reference journey (percentage of travel time)

\begin{tabular}{|c|c|c|}
\hline & Commute $(\%)$ & Other $(\%)$ \\
\hline \multicolumn{3}{|l|}{ Activities using printed matter } \\
\hline Read book/magazine/newspaper & 18 & 15 \\
\hline \multirow[t]{2}{*}{ Study/work related reading } & 9 & 2 \\
\hline & 27 & 17 \\
\hline \multicolumn{3}{|l|}{ Eating/drinking } \\
\hline Eating/drinking & 5 & 7 \\
\hline \multicolumn{3}{|l|}{ Activities using a phone } \\
\hline Talked/texted on phone & 12 & 8 \\
\hline \multicolumn{3}{|l|}{ Smart phonelebook/tablet/computer activities } \\
\hline Worked & 7 & 1 \\
\hline Read/wrote emails & 6 & 2 \\
\hline Browsed the internet & 7 & 5 \\
\hline Watched video/listened to music & 7 & 6 \\
\hline Played games/puzzles & 3 & 3 \\
\hline \multirow[t]{2}{*}{ Read book } & 3 & 3 \\
\hline & 33 & 20 \\
\hline \multicolumn{3}{|l|}{ Talking } \\
\hline Talked to travelling companions & 3 & 19 \\
\hline \multirow[t]{2}{*}{ Talked to other passengers } & 3 & 2 \\
\hline & 6 & 21 \\
\hline \multicolumn{3}{|l|}{ Relaxation } \\
\hline Did nothing (day dreamed, looked out of window) & 10 & 16 \\
\hline \multirow[t]{2}{*}{ Slept or snoozed } & 4 & 4 \\
\hline & 14 & 20 \\
\hline \multicolumn{3}{|l|}{ Other } \\
\hline Looked after children/accompanying passenger(s) & 0 & 4 \\
\hline \multirow[t]{2}{*}{ Thinking and/or Planning things } & 3 & 3 \\
\hline & 3 & 7 \\
\hline
\end{tabular}

The figures in bold are the subtotals for generic categories

Table 4 indicates the proportion of train time devoted to each of 16 specific activities (in italics) and 7 generic activities (in capitals). The spread across specific activities is fairly even, although the proportions of commuters' travel time spent reading books, magazines or newspapers, talking or texting on a phone, and doing nothing stand out as do talking to travelling companions, doing nothing and reading books, magazines or newspapers for other travellers. Activities dependent upon group travel include talking with travelling companions, which might be regarded to be similar to talking to other passengers, as well as the potentially more onerous but far less time significant task of looking after children and others.

As for generic activities, commuters spend $45 \%$ of their time on those based around mobile technology and phones, with printed matter taking this to $72 \%$. For other travellers, only $28 \%$ of time was spent using mobile devices and phones, somewhat outweighed by the $41 \%$ of time spent talking or relaxing. There would therefore seem to be considerable scope for further increases in the amount of time spent using mobile devices should travellers wish to do so. 
Table 5 On-train activities by duration of reference journey (percentage of travel time)

\begin{tabular}{|c|c|c|c|c|c|c|}
\hline & \multicolumn{3}{|l|}{ Commute } & \multicolumn{3}{|l|}{ Other } \\
\hline & $\begin{array}{l}\leq 30 \min \\
\mathrm{n}=180 \\
(\%)\end{array}$ & $\begin{array}{l}31-75 \min \\
\mathrm{n}=234 \\
(\%)\end{array}$ & $\begin{array}{l}>75 \min \\
\mathrm{n}=157 \\
(\%)\end{array}$ & $\begin{array}{l}\leq 30 \min \\
\mathrm{n}=318 \\
(\%)\end{array}$ & $\begin{array}{l}31-75 \mathrm{~min} \\
\mathrm{n}=539 \\
(\%)\end{array}$ & $\begin{array}{l}>75 \mathrm{~min} \\
\mathrm{n}=565 \\
(\%)\end{array}$ \\
\hline Printed matter & 27 & 26 & 30 & 11 & 17 & 20 \\
\hline Eating/drinking and other & 10 & 8 & 9 & 11 & 14 & 15 \\
\hline Activities using a phone & 10 & 12 & 13 & 12 & 9 & 6 \\
\hline Digital devices & 31 & 35 & 30 & 18 & 19 & 22 \\
\hline Talking & 5 & 5 & 6 & 28 & 23 & 16 \\
\hline Relaxation & 17 & 14 & 12 & 20 & 18 & 21 \\
\hline
\end{tabular}

Table 6 Use of train time to save time in activities elsewhere (percentage of respondents)

\begin{tabular}{lll}
\hline & Commute (\%) & Other (\%) \\
\hline $\begin{array}{l}\text { Use train journeys a lot for } \\
\text { specific tasks }\end{array}$ & 21 & 7 \\
$\begin{array}{l}\text { Use train journeys a bit for } \\
\text { specific tasks }\end{array}$ & 35 & 26 \\
No & 44 & 67 \\
\hline
\end{tabular}

Table 5 provides an indication as to how the proportion of time spent on generic activities varies across short, medium and longer distance trips. Eating and drinking has been merged with other given that each covered small proportions of time in Table 4. The proportions vary little by duration band for commuting with perhaps the exception of relaxation becoming less common as duration increases. There is a little more variation for other trips, with printed matter becoming continuously more important as journey length increases and the reverse the case for talking. Whilst these relationships seem credible, in general there is on average little variation in how time is spent according to the duration of the train journey.

Finally, we asked if train time was used to do specific tasks to save time elsewhere. Table 6 indicates that the majority of commuters exploit train travel time to save time elsewhere, which is presumably driven by undertaking work-related activities, whereas only a third of travellers for other purpose do so.

\section{Survey findings}

We identified some respondents with 'odd' combinations of short (long) travel times associated with high (low) travel costs along with some who reported per journey travel costs less than $£ 2$ or greater than $£ 200$. These would have transferred to the SP exercises and resulted in unrealistic choice scenarios. Removing these individuals reduced the sample by $15 \%$ to 1688 individuals. Multinomial logit models have been estimated to the SP data using the Biogeme package (Bierlaire 2003) with allowance for repeat observations per person. 
Table 7 Standard SP1 exercise

\begin{tabular}{lcccc}
\hline & Base & Proportional & Incremental & Activity \\
\hline Time (min) & $-0.067(12.8)$ & & & $-0.057(9.7)$ \\
Time electronic devices & & $-0.084(8.9)$ & $-0.083(9.1)$ & \\
Time printed matter & & $-0.082(7.4)$ & $-0.079(7.8)$ & \\
Time talking & & $-0.046(4.1)$ & $-0.062(4.9)$ & \\
Time other & & $-0.074(4.4)$ & $-0.049(4.6)$ & \\
Time doing nothing & & $-0.046(3.9)$ & $-0.061(7.3)$ & \\
Time a lot & & & & $-0.011(1.1)$ \\
Time a bit & $-0.014(1.8)$ & $-0.007(0.9)$ & $-0.012(1.4)$ & $-0.029(3.9)$ \\
+ Time commute & $-11.380(2.6)$ & $-10.394(2.5)$ & $-11.120(2.5)$ & $-11.320(2.5)$ \\
Cost (£) & $0.218(5.5)$ & $0.209(5.3)$ & $0.216(5.5)$ & $0.218(5.6)$ \\
Income elasticity $(\lambda)$ & 0.111 & 0.114 & 0.112 & 0.115 \\
Adjusted $\rho^{2}$ & -4155.94 & -4140.12 & -4149.21 & -4135.88 \\
Log-likelihood & $6752(1688)$ & & & \\
Observations (individuals) & & &
\end{tabular}

$\mathrm{t}$ ratios in parentheses

\section{SP1 standard VTTS experiment}

This SP exercise examines VTTS variations across individuals and therefore does not allow for endogeneity. The key variables in our data set that are expected to drive variations in VTTS and which could be linked to endogeneity are income and journey purpose and hence these need to be accounted for. Given that income is expected to impact on the sensitivity to cost and journey purpose on the sensitivity to time, the utility function for alternative $\mathrm{i}\left(\mathrm{U}_{\mathrm{i}}\right)$ in the Base model in Table 7 takes the form:

$$
U_{i}=\alpha \text { Time }_{i}+\beta d_{k i} \text { Time }_{i}+\gamma \frac{\text { Cost }_{i}}{Y_{k}^{\lambda}}
$$

$\mathrm{d}_{\mathrm{ki}}$ is a dummy variable denoting whether respondent k's journey purpose was commuting and hence the sensitivity to time variations is $\alpha$ for other trips and $\alpha+\beta$ for commuting. The sensitivity to cost depends upon respondent k's household income $\left(\mathrm{Y}_{\mathrm{k}}\right)$ with $\lambda$ denoting the elasticity of VTTS with respect to income. The VTTS for respondent $\mathrm{k}$ is:

$$
\operatorname{VTTS}_{k}=\frac{\alpha+\beta d_{k}}{\gamma} Y_{k}^{\lambda}
$$

The coefficient estimates in the Base model have the expected sign and, with the exception of the incremental effect for commuting, are significant at the $5 \%$ level with the commuting term significant at the $10 \%$ level. The goodness of fit is, in our experience, in line with what is typically achieved by comparable models.

Given a mean annual household income of around $£ 37,000$, the implied mean VTTS for commuting and other are $£ 0.071$ and $£ 0.058$ per minute. These are around half those estimated in the most recent UK national VTTS study for rail travel in 50\% load factor conditions (ARUP et al. 2015). This might be a function of the panel survey recruitment 
process, ${ }^{11}$ although a lesser average household income here of around $£ 8000$ per annum and generally shorter journeys will have contributed.

Nevertheless, the focus of our study is not absolute VTTS but variations in VTTS. Whilst the very precisely estimated income elasticity of 0.218 might be deemed to be low, it is broadly in line with the 0.30 for both commuting and other trips for rail travellers reported by ARUP et al. (2015). The usual argument for low cross-sectional income elasticities is that there will be some who have a high utility of money who strive for higher incomes. A further explanation here is that higher income rail travellers might make more use of activities, and indeed better quality activities, that operate to reduce the VTTS.

Whilst it might be argued that a low income elasticity could result from cost variations that are insufficient to allow those with higher incomes to demonstrate somewhat lower sensitivity to cost, this is not the case here since the mean absolute difference in cost between the two options as a proportion of the fare paid was $15 \%$, with 5th, 25th, 75th and 95th percentiles of $3 \%, 6 \%, 18 \%$ and $32 \%$.

We explored whether there were variations in VTTS according to the sign and size of the time variations but there was no convincing support for such variations. Nor did the VTTS vary significantly according to the reference trip journey time or crowding although relatively few experienced the latter and even then it would not always be for the whole journey. It might also be argued that the VTTS varies with, say, the degree of travel time reliability, whether an interchange was required, and whether the journey was intermodal and the degree of access and egress time. However, we did not collect information on these. It is though worth bearing in mind, for this and subsequent analysis, that we are here interested in differences in VTTS due to multitasking and such differences can be expected to be less sensitive to these potential influential variables than the absolute VTTS estimates themselves.

One of the variables that has been tested in previous studies (Wardman and Lyons 2016) that might proxy for worthwhile use of time is group travel. Travelling with others can make for a more pleasurable journey, thereby reducing MVT of Eq. 1, although the reverse might apply if there is a requirement to look after accompanying travellers. An incremental effect on time was specified to represent those who travelled just with other adults and whilst this indicated a lower disutility of travel time it was not statistically significant.

The Proportional model can be taken to represent a conventional approach to segmentation of VTTS according to the activities undertaken while travelling. The latter are the generic activities of Table 4, combined into 5 categories as a result of merging phone use with other electronic devices and reallocating the small sample in the Eating and Drinking category to Other. Rather than segment journey time just by the main activity, ${ }^{12}$ as has been done in some previous studies, we used the reported proportion of time spent in each category to prorate the journey time and specify absolute amounts of each and denoted by

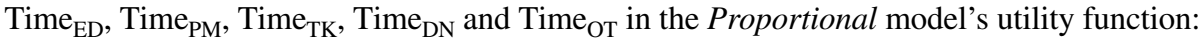

$$
U_{i}=\alpha_{1} \text { Time }_{E D i}+\alpha_{2} \text { Time }_{P M i}+\alpha_{3} \text { Time }_{T K i}+\alpha_{4} \text { Time }_{D N i}+\alpha_{5} \text { Time }_{\text {OTi }}+\beta d_{k i} \text { Time }_{i}+\gamma \frac{\text { Cost }_{i}}{Y_{k}^{\lambda}}
$$

\footnotetext{
11 Douglas and Jones (2018) found the VTTS of rail users to be $31 \%$ less when the SP exercise was completed as part of an online panel compared to an on-train self-completion survey.

12 It turned out that it did not make a great deal of difference to the results obtained when the main activity was used instead.
} 
Table 8 Strategic SP2 exercise

\begin{tabular}{lll}
\hline & Coeff $(\mathrm{t})$ & Value $(\mathrm{t})$ \\
\hline Time as now & $-0.054(10.6)$ & $0.81(9.6)$ \\
Time no electronic devices & $-0.064(11.3)$ & $0.96(9.9)$ \\
Time doing nothing & $-0.067(10.9)$ & Base \\
Adjusted $\rho^{2}$ & 0.043 & \\
Observations & 6752 & \\
Individuals & 1688 & \\
\hline
\end{tabular}

Value denotes the coefficient estimate relative to the base. $t$ ratios in parentheses

The $\alpha$ terms represent absolute effects and $\beta$ is a common increment to be applied to all the $\alpha$ terms to allow for commuting. According to a likelihood ratio test, this leads to a statistically superior model, unsurprising given that all five time coefficients are very precisely estimated and the Time Electronic Devices and Time Printed Matter coefficient estimates are both significantly different from those for Time Doing Nothing and Time Talking. ${ }^{13}$ However, we would not expect Time Electronic Devices and Time Printed Matter to be associated with higher disutility than Time Doing Nothing and Time Talking.

The Incremental model is based on what respondents stated they would do (forego) in the extra (saved) time, as discussed in "The stated preference exercises" section, interacting the gains and losses on the current journey time according to the same five generic categories as the Proportional model. The utility function is therefore the same as Eq. 4 albeit with the time terms defined differently. Whilst we might expect this original use of 'marginal' activities to be preferable to the 'average' activities of the Proportional model, this is not so statistically. The differences between the Time Electronic Devices and Time Other and between the Time Printed Matter and Time Other are significant, but again these relationships are not credible.

Whilst there might be confounding effects even after accounting for income and journey purpose, these results do confirm our concerns regarding endogeneity. In particular, we would point out that Time Printed Matter and Time Electronic Devices have the largest coefficients in both the Proportional and Incremental models, and whilst these activities might be expected to reduce the disutility of travel time the most they are also likely to be the activities that those with high VTTS engage in on their train journeys.

We also investigated whether train time was used to save time doing activities elsewhere, which operates more on the RVT term of Eq. 1 by increasing the effective amount of time available. What we term the Activity model is based on Eq. 2 but specifies two additional incremental terms of Time a Lot and Time a Bit to denote whether time on train was used a lot or a bit in order to save on time doing activities elsewhere. Both these coefficient estimates are wrong sign since more time pressured travellers who find travel time valuable should value savings in it less all else equal. We again conclude that this reflects endogeneity bias.

We now turn to the SP exercises that allow analysis of within-person variations in VTTS due to multitasking.

${ }^{13}$ All four $\mathrm{t}$ ratios for the difference in coefficient estimates were in the range 2.3 to 2.7 . 


\section{SP2 strategic experiment}

The results for the SP2 strategic exercise are reported in Table $8 .{ }^{14} \mathrm{~A}$ standard linear-additive utility function, of the form of Eq. 4 without the final two terms relating to the $\beta$ increment and cost, was estimated representing train journey time in three different conditions and all three coefficients are estimated very precisely. Constant terms were not significant whilst the only significant incremental effect for commuting was on the Time Doing Nothing coefficient but it was not retained given it implied only a 5\% variation. There were no significant variations according to group travel or degree of crowding.

The Time No Electronic Devices coefficient estimate is larger than that for Time as Now, albeit not quite significantly different at the $5 \%$ level with a t ratio of 1.8 , and it implies an $18.5 \%$ increase in VTTS. Whilst this could be regarded to be a relatively low figure, it will have been influenced by only $33 \%$ of train time on average engaged with mobile devices whilst the alternative activities, as discussed in "Comparison of SP2 and SP3 valuations" section, might for some respondents be good substitutes.

The Time Doing Nothing coefficient estimate is only slightly larger than that for Time No Electronic Devices, which is surprising given 67\% of train time on average does not involve mobile devices. Possible unrealism of a doing nothing alternative is not the explanation since this would only add to its disutility.

SP2 was a strategic exercise aimed at providing a high level indication of the dis-benefits of being unable to use mobile devices ${ }^{15}$ and the inability to do anything. It was the purpose of the SP3 exercise to segment VTTS more specifically by engaged activities and it is to this that we now turn.

\section{SP3 tactical experiment}

The tactical SP exercise offered choices between Option A containing 2, 3, 4, 5 or 6 specific activities, driven by the range undertaken in the reference train journey, and Option $\mathrm{B}$ containing one less activity, with 53\% offered 2 versus 1 activities, and respectively $27 \%$, $11 \%, 5 \%$ and $4 \%$ offered the other comparisons through to 6 versus 5 activities. Hence the vast majority were offered an SP exercise containing 4 or fewer activities.

Whilst we presented many different specific activities in this SP exercise, attempting to estimate robust coefficients for each of them proved unfruitful, as might be expected. Instead, we segmented by the same 5 generic categories as in SP1.

We might hypothesise that SP scenarios containing more activities involve greater difficulty in making a choice. Even if this is random error, it presents a potential problem for choice modelling given that the coefficient estimates are scaled relative to the amount of residual variation. If some activities are associated with more difficult choice tasks and therefore attract more residual variation then their coefficient estimates will be biased due to this confounding.

We estimated scales for four of the five different combinations of alternatives, with the comparison of 6 against 5 activities arbitrarily set to one. Only the scale for the

\footnotetext{
${ }^{14}$ For those who do not use mobile devices, options $\mathrm{A}$ and $\mathrm{B}$ are the same, whilst all options are the same for those who do nothing. The former turned out to be $24.8 \%$ of the sample and the latter only $3.3 \%$. Removing these respondents made very little difference to the results.

15 As well as a novel direct comparison with behavioural intentions in the event that mobile devices could not be used.
} 
Table 9 Tactical SP3 Exercise

\begin{tabular}{lll}
\hline & Coeff $(\mathrm{t})$ & Value $(\mathrm{t})$ \\
\hline Time electronic devices & $-0.040(12.0)$ & $0.69(9.9)$ \\
Time printed matter & $-0.042(12.2)$ & $0.72(10.3)$ \\
Time talking & $-0.046(11.9)$ & $0.79(10.1)$ \\
Time other activities & $-0.055(8.9)$ & $0.95(7.8)$ \\
Time doing nothing & $-0.058(12.5)$ & Base \\
Adjusted $\rho^{2}$ & 0.132 & \\
Observations & 5028 & \\
Individuals & 1257 & \\
\hline
\end{tabular}

Value denotes the coefficient estimate relative to the base. $t$ ratios in parentheses

comparison of 3 against 2 activities, of 1.48, was significantly different from one and its inclusion, or indeed the full set, made very little difference to the relative valuations and so none were retained.

It might also be speculated that respondents are more likely to ignore attributes the more of them characterise an alternative, which might be regarded to be a systematic error. We found no clear evidence supporting the presence of such effects.

A contributory factor underpinning these findings is that the alternatives presented to respondents contained a wide variety of specific activities and so none were specifically suspect to scale effects or systematic bias.

The estimated model for SP3 is reported in Table 9 and takes the same standard linear-additive form as SP2 which is Eq. 4 without the final two terms relating to the $\beta$ increment and cost. This SP exercise was only offered to those who engaged in more than one activity that took $10 \mathrm{~min}$ or more and hence the sample is $26 \%$ lower than for SP1 and SP2. We were unable to discern any significant journey purpose, group travel or crowding incremental effects.

The coefficients are estimated with a high degree of precision and the relative VTTS seem plausible. The Time Electronic Devices coefficient indicates that spent in this activity has the lowest disutility, as might be expected, but the Time Printed Matter coefficient implies that activities involving printed matter are regarded to be very similar. Whilst electronic devices support a broader range of activities, some will prefer newspapers, printed papers and books to their laptop, tablet, e-reader and mobile phone equivalents. These coefficient estimates are significantly different to Time Doing Nothing, with t ratios of 3.4 for both. Time Talking has a slightly larger disutility but is also significantly different $(\mathrm{t}=2.4)$ to Time Doing Nothing. Time Other Activities is only a little different to Time Doing Nothing, which we attribute to it including looking after others. ${ }^{16}$ It is also though significantly different to the Time Electronic Devices and Time Printed Matter coefficient estimates, with t ratios around 2.2, but not the Time Talking coefficient estimate.

Compared to Time Doing Nothing, the other time coefficients vary not only in the expected direction but the magnitude of the variations, with a maximum of a $31 \%$ reduction

\footnotetext{
${ }_{16}$ The sample size for those looking after others was too small to support robust estimation of a separate time coefficient.
} 
Table 10 Demand impactsswitching from rail for reference trip

\begin{tabular}{lcc}
\hline & Commute (\%) & Other (\%) \\
\hline Overall & 13.2 & 9.0 \\
Mobile time use $\leq 20 \%$ & 10.7 & 3.3 \\
Mobile time use 21-50\% & 13.3 & 15.5 \\
Mobile time use $>$ 50\% & 15.2 & 11.6 \\
Train time $<30$ min & 7.0 & 7.6 \\
Train time 31-60 min & 10.8 & 4.4 \\
Train time 61-120 min & 24.1 & 15.6 \\
Train time over 120 min & 28.7 & 12.2 \\
Use train time a lot & 23.2 & 12.2 \\
Use train time a bit & 15.6 & 12.7 \\
No use of train time & 5.5 & 6.1 \\
\hline
\end{tabular}

in travel time disutility, seem reasonable. To place this figure in context, the Great Britain railway industry's PDFH (Rail Delivery Group 2018) would indicate such a reduction in rail VTTS to be comparable to transforming a standing journey in conditions of 1 standing passenger per metre squared on London and South East and on regional services to conditions of seated in a half full train.

\section{Behavioural Responses to Inability to Use Mobile Devices}

Table 10 reports the proportionate reductions in demand if mobile devices could no longer be used. The proportionate reduction is larger for commuters, which is in line with their somewhat greater use of mobile devices as apparent in Table 4. Whilst a 13.2\% demand reduction would be deemed too large for commuting to Central London, where rail is in a strong position, only a third of our commuting sample is to Central London. The variations in demand response according to mobile time usage, train journey time and the extent to which train time is used to save time undertaking activities elsewhere are broadly sensible which is encouraging with regard to the validity of the response supplied.

\section{Stimulus of new trips}

Given the hypothesis that rail has become more attractive as a result of the digital revolution, we asked respondents whether they had perceived "over recent years" more possibilities for doing "worthwhile things" while travelling by train and, if so, the extent to which this had generated more train trips.

We did not think it practical to frame the question to cover improvements over the period of the digital revolution, which would have made responses comparable to the behavioural intentions question, partly because of uncertainties defining this period but mainly because of the recall difficulties that would be involved. With hindsight though we should have been more specific on what we meant by recent years.

The behavioural question regarding new trips and the extent of current trip making did not distinguish by journey purpose. After removing 168 who did not state how many extra trips they would make, we have a sample of 1825 respondents. Of these 1439 (79\%) felt that there had been more possibilities for worthwhile activities and $456(25 \%)$ stated that they had made more rail trips in recent years as a result of it. In total, the 1825 individuals 
made 77,921 rail trips per annum, an average of 43 per person, and reported making 1718 additional trips, implying a $2.3 \%$ increase in rail demand. Given that recent years might not be many, this figure represents an appreciable annual increase in rail demand.

\section{Synthesis of evidence}

We here provide a synthesis of the new evidence reported above, assessing its internal consistency and the extent to which it might contribute to understanding of VTTS and demand changes over time.

\section{Comparison of SP2 and SP3 valuations}

SP2 in Table 8 provides a direct estimate of Time Doing Nothing being valued $24.1 \%$ higher than Time As Now. For the equivalent comparison for SP3, we need to deduce the implied time coefficient for the as now situation. Given that the proportions of the current train time engaged in the various activities is $33 \%$ electronic devices, $20 \%$ printed matter, $18 \%$ doing nothing, $17 \%$ talking and $12 \%$ other, the SP3 time coefficients in Table 9 imply an average of -0.046 . The Time Doing Nothing coefficient of -0.058 is $26.1 \%$ larger, very similar to the SP2 figure.

We can follow the same process in comparing the SP2 and SP3 valuations of Time As Now and Time No Electronic Devices. When asked what they would do if unable to use mobile devices, the proportions were $27 \%$ printed matter, $32 \%$ doing nothing, $19 \%$ talking and $22 \%$ other, implying an average SP3 time coefficient of -0.051 which is $10.9 \%$ larger than the -0.046 implied for the as now situation. This effect implied by SP3 is somewhat less than the $18.5 \%$ effect in SP2. Given the surprisingly small difference between Time No Electronic Devices and Time Doing Nothing in SP2, and the consistency between SP2 and SP3 in comparing Time As Now and Time Doing Nothing, we might conclude it is Time No Electronic Devices that is too large rather than the Time Doing Nothing too low.

\section{Comparison of stated preference and behavioural intentions}

With regard to the consistency of the demand and valuation evidence, we can compare the direct estimates of the demand impacts of not being able to use mobile devices with indirect estimates deduced using the valuation evidence from SP2.

The demand impacts of not being able to use mobile devices were $13.2 \%$ for commuters and $9.0 \%$ for other journeys, as set out in Table 10. The SP2 exercise reported in Table 8 found that the inability to use mobile devices increased the VTTS by $18.5 \%$, and given that the Wardman (2012) meta-analysis would, for average distances in our sample of around 30 miles for commuting and 65 miles for other, yield long run time elasticities of around -0.80 and -0.90 respectively, the deduced demand reductions are $12.7 \%$ for commuters and $14.2 \%$ for others. Whilst the former is close to the direct estimate, the latter is not. Overall, the direct estimate averages a $10.2 \%$ demand impact which is lower than the $13.8 \%$ for the indirect estimate but not unreasonably so. Whilst there may be other factors at work which impact on this comparison, such as uncertainties surrounding time elasticities and sampling distributions of estimates, the finding is consistent with the comparison of the SP3 and SP2 valuations of not being able to use mobile devices reported in "Comparison of SP2 and SP3 valuations" section which indicated that the latter might be too 
large. Consistency of the direct and indirect demand effects would require that the SP2 VTTS variation is $13.2 \%$ rather than $18.5 \%$.

\section{SP findings and value of time over time}

We should speculate as to how the VTTS might have varied over time, given this is a primary impetus to the research. There is little information on how activities have varied over time, so the detailed results of SP3 are not directly useful in this regard. A sensible approach would be to compare the current situation with no digital devices. The movement from no digital devices to the current (2014) situation reduces the VTTS by $15.6 \%$ in Table 2 using the SP2 direct evidence but by $11.7 \%$ if it is rescaled to be consistent with our demand evidence as set out in "Comparison of stated preference and behavioural intentions" section. The latter is in line with the 9.8\% VTTS reduction implied by SP3 for the as now and no digital devices situations in "Comparison of SP2 and SP3 valuations" section.

If we take the digital revolution to have started in 2000, these three figures imply $1.20 \%$, $0.88 \%$ and $0.73 \%$ annual reductions in VTTS respectively. Taking the starting point as 2005 yields corresponding figures of $1.87 \%, 1.37 \%$ and $1.14 \%$. It would be reasonable to conclude that these sorts of annual reductions would not in 'normal years' offset the VTTS increases attributed to income growth but that they would make a considerable dent in them and make a strong contribution to the findings of repeat studies that demonstrate much less than expected growth in VTTS.

\section{Demand impacts}

We can compare the behavioural intentions due to inability to use mobile devices as discussed in "Behavioural responses to inability to use mobile devices" section and the actual behaviour reported to result from more worthwhile activities in 'recent years' as discussed in "Stimulus of new trips" section. We must note though that:

- The two questions have different time dimensions; the removal of digital devices can be seen to represent a long term effect in excess, perhaps appreciably so, of recent years.

- Recent years could be expected to have experienced diminishing returns, and this would be in line with product life-cycle models in marketing.

- Worthwhile activities are more than just those benefitting from mobile devices, although the digital revolution is likely to be the main if not overwhelming contributory factor.

- Losses might be valued more highly than gains, given that travellers have got used to journeys with their mobile devices.

- A risk surrounding behavioural intentions is that they are subject to exaggeration due to strategic bias and protest responses, although in this context we might expect the incentives to be slight. On the other hand, the reporting of actual behavioural change might be impacted by poor recall.

"Stimulus of new trips" section reports a $2.3 \%$ increase in rail demand in recent years due to perceived increases in being able to do worthwhile activities during a train journey. This falls well short of the $10.2 \%$ demand loss (11.4\% demand increase), as an average of the commute and other figures in Table 10, for the same sample if mobile devices cannot be used. We would though argue that recent years are no more than five and the mobile 
revolution might go back to 2000 in which case the $2.3 \%$ increase if extended over a time period three times as long would imply a $7.1 \%$ demand increase. The difference might then be reconciled by some loss aversion, diminishing returns and response error.

We also have indirect demand forecasts obtained from the SP findings. In moving from no digital devices to the current situation, the SP2 exercise reported in Table 8 implies a $15.6 \%$ reduction in VTTS whilst the equivalent figure for SP3 as is apparent in "Comparison of SP2 and SP3 valuations" section is $9.8 \%$. These would imply sizeable demand changes and using the long run elasticities of "Comparison of stated preference and behavioural intentions" section, of -0.80 for commuting and -0.90 for other, leads to forecast increases in commuting trips of $14.5 \%$ and $8.6 \%$ respectively, with corresponding figures of $16.5 \%$ and $9.7 \%$ for other trips. The averages in our sample across journey purpose are $15.9 \%$ and $9.4 \%$ respectively. These all imply appreciable increases in rail demand over time which can be deemed to be longer run and provide narrow bounds around the $11.4 \%$ direct estimate.

As for consistency with historic rail demand changes, after accounting for the effects of variations in fare, timetable related service quality, income, employment, population, car cost, car time and a number of socio-economic factors, there remained residual increases in rail demand in econometric models of very large amounts of sales data over the period 2000 to 2014 (Leigh Fisher et al. 2016). As a result, some significant time trends were recovered when subsequently estimated (SYSTRA and ITS Leeds 2018). These were 1.5\% per annum for long distance flows, $0.7 \%$ for commuting to London, $4.6 \%$ for commuting to major regional centres, ${ }^{17}$ and $2.6 \%$ and $2.0 \%$ for non-season tickets in the South East to London and shorter journeys elsewhere.

As a broad average, our direct estimate of an $11.4 \%$ increase over the period seems a reasonable figure to use, not least because it is bounded by the indirect evidence from the SP exercises. It would imply $0.77 \%$ increase in demand per annum over the period 2000-2014. In line with the evidence relating to VTTS variations over time, we conclude that the mobile revolution cannot account for all the unexplained rail demand increases but it can make a significant contribution. We are not aware of other quantifications of the unaccounted for strong rail demand growth.

\section{Concluding remarks}

The research reported here has been concerned with how the worthwhile use of travel time might impact on the value of travel time savings for personal travel (VTTS) and on demand, set in the context of the rail travel market in Great Britain. Its significance lies in dealing with key parameters of transport planning and appraisal about which there has been much uncertainty in recent years.

There is a very large body of evidence that indicates that travellers make use of travel time and that this impacts on their journey satisfaction whilst a number of exact repeat VTTS studies hypothesise that improvements in the worthwhile use of time over time, particularly related to the digital revolution, have dampened or even reversed growth in VTTS.

\footnotetext{
17 This very high figure is most likely the result of major structural changes in the employment market in the period in question, leading to large increases in rail commuting into major centres, combined with a lack of accurate data on how employment had grown in these centres. Parking restrictions, increased parking charges and localised congestion might also have had a bearing.
} 
Moreover, the rail travel market in Great Britain has witnessed strong but unexplained demand growth, which some observers have attributed to the digital revolution.

Although conventional economic theory readily accommodates variations in the VTTS according to the extent to which travellers can engage in worthwhile activities, we are not aware of official appraisal guidance that permits it. Indeed, there is little empirical evidence on the subject.

Almost all the previous investigations have used as their source of variation different activities done by different people. The problem is that this suffers from endogeneity bias, since those with higher disutilities of travel time or more constraints upon their time are more likely to undertake worthwhile activities while travelling. This will then confound VTTS variations drawn from between individual comparisons and we contend that this bias is apparent in the reviewed empirical evidence. Moreover, previous research suffers both from being unclear as to what the offered time variations actually represent in terms of journey activities and how they impact on the marginal VTTS.

Our approach is, as far as we are aware, original ${ }^{18}$ in that it adopts the recommendations of Wardman and Lyons (2016) and explores within individual variations in activities. Indeed, one of the Stated Preference (SP) exercises undertaken here that is not restricted to within individual comparisons, despite being novel in terms of linking lost (gained) time to the activities that would be undertaken (foregone) in that time, provides relative VTTS estimates that seem to have been strongly influenced by endogeneity bias. Other novel features are that we have covered more activities than previous studies, even though we have grouped specific activities into generic categories for pragmatic estimation purposes, and we have explored the impact of a change, namely the absence of electronic devices, in a manner that is directly comparable across VTTS and travel demand.

Our two SP exercises that do control for endogeneity obtain new insights and generally plausible variations in VTTS, as do the behavioural questions relating to demand response. Whilst the results from our different approaches are not entirely consistent, this is a not uncommon feature of adopting different means of exploring the same issue, and indeed some might say it is an inevitable outcome. We therefore need to look at the 'bigger picture' of emerging evidence, not least bearing in mind that what might be regarded as the 'naïve' approach, as typified by our SP1 exercise, yields wholly unsatisfactory results. In terms of the motivation for this research, the evidence supports the following key conclusions:

- There have been modest rather than considerable reductions over time in VTTS due to the digital revolution. Whilst these cannot offset the increases in VTTS over time that have been ascribed to income growth, they do make a significant contribution to explaining the findings of repeat studies that demonstrate less than expected growth in VTTS over time as well as addressing theoretical expectations.

- Rail demand in Great Britain, which provides our behavioural case study, has witnessed significant unexplained increases in recent times. Whilst our findings regarding demand increases driven by reductions in VTTS due to the digital revolution cannot account for all of the demand growth, in line with case for VTTS variations they would make a significant contribution to explaining what has happened in practice.

\footnotetext{
18 Whilst one study (Adjenughwure 2017) also adopted the Wardman and Lyons (2016) recommendation regarding endogeneity, it is pre-dated by this study. It also differs from this study in a number of respects.
} 
In summary, we contend that the digital revolution has had a significant, but largely unaccounted for, impact on key parameters of transport planning and appraisal. But what of the future for VTTS and the worthwhile use of time? There would seem to remain possibilities for further reductions in VTTS for both quantity and quality reasons.

Firstly, not everyone is making use of digital devices, although a complicating factor is that not all will want to or be in a position to do so. In our sample, mobile device usage covers $33 \%$ of travel time and around two-thirds of commuters and $44 \%$ of other travellers felt that at least part of their journey was wasted with around $40 \%$ of these citing limitations in being able to use their mobile devices as causal factors. Whilst there is scope for further use of mobile devices while travelling, we must bear in mind that our evidence indicates a maximum reduction of $31 \%$ in the VTTS from transferring from entirely doing nothing to entirely using electronic devices, and less than $20 \%$ of time is spent doing nothing. Nonetheless, we might expect VTTS to continue to fall over time, all else equal, due to increased opportunities to use time in a worthwhile fashion and given cohort effects of people accustomed to mobile devices.

Secondly, future developments in digital devices, and indeed the activities that such devices support, might be expected to lead to further reductions in the disutility of time spent travelling and in the possibilities to undertake activities which save time elsewhere. So even if diminishing returns applies to the growth in the quantity of mobile device use, improvements in the quality dimension can be expected to operate.

The research reported here is a first step in exploring how worthwhile use of time impacts on VTTS given allowance for endogeneity. There is scope for considerable further research and we would point out a few in the area.

We combined different activities into generic activities in the estimation process and a sensible avenue of future research would be to estimate relative VTTS for more specific activities. We have only considered the quantity of different activities and further research relating to the quality of activities is a priority. Indeed, it is important to understand what travellers' preferences are between different activities for in-journey time and the barriers they face in engaging in them.

The research here has focussed on rail travel but it could be extended to other modes. In particular, the advent of automated cars can be expected to have a significant effect on VTTS and demand due to a transformation in the ability to undertake worthwhile activities while travelling. Appraisal practice will be unable to ignore such developments.

There are a wide range of influences on the VTTS but the focus here has been on demonstrating the impact of worthwhile use of time on VTTS with limited analysis of other influences and indeed how they might interact with the impact of worthwhile use of time. Further research should consider variations in VTTS due to multitasking alongside factors that could influence that variation, such as group travel and the need to look after accompanying travellers, leg of journey, degree and type of crowding and how this interacts with specific activities, travel time reliability, whether the journey is inter-modal or requires interchange, time pressures, and the activities that can be undertaken as a result of multitasking on train journeys. There is scope for further analysis of non-linearities and thresholds which impact on the beneficial impacts of multitasking. However, appropriately incorporating worthwhile use of time routinely in SP studies dealing with travel time would seem to add somewhat to their complexity given that allowing for endogeneity is not a simple task. In addition, more attention needs to be paid to what drives the amount of time spent doing different worthwhile activities and how these might vary in future. Whilst we had to resort to an online panel for resource reasons, examination of these detailed issues 
requires recruitment of respondents during their journeys for the best recall and customisation purposes.

Finally, the evidence here would affirm what seems to be the current practice in Western European countries of undertaking periodic national VTTS studies rather than relying on updates to recommended VTTS based largely around income growth.

Acknowledgements The authors are grateful for the financial support provided by the Passenger Demand Forecasting Council of the UK Rail Industry's Rail Delivery Group that matched the funding provided by Accent's support of Dr Chintakayala's research post. Tony Magee of the Rail Delivery Group and Rob Sheldon of Accent provided guidance during the Project and Peter Mackie provided valuable comments on a draft version of the paper. We are indebted to Robert Fickling, now of Transport for Greater Manchester, for raising with us the issues and ideas researched here.

Author contributions MW Choice Experiment Design, Literature Search and Review, Analysis, Manuscript Writing. PC Choice Experiment Design, Survey Design, Choice Model Analysis. CH Survey Design, Data Collection Process, Data Descriptives.

\section{Compliance with ethical standards}

Conflict of interest The authors declare that they have no conflict of interest.

Open Access This article is distributed under the terms of the Creative Commons Attribution 4.0 International License (http://creativecommons.org/licenses/by/4.0/), which permits unrestricted use, distribution, and reproduction in any medium, provided you give appropriate credit to the original author(s) and the source, provide a link to the Creative Commons license, and indicate if changes were made.

\section{References}

Adjenughwure, K.: The monetary value of a pleasant and productive train trip: developing an experimental method for estimating monetary values of activities performed during travel. Masters Thesis, Delft University of Technology (2017)

ARUP, ITS University of Leeds and Accent.: Provision of market research for value of travel time savings and reliability: phase 2 report. Prepared for the Department of Transport. (2015). https://assets.publi shing.service.gov.uk/government/uploads/system/uploads/attachment_data/file/470231/vtts-phase -2-report-issue-august-2015.pdf. Accessed 19 Nov 2018

Batley, R., Bates, J., Bliemer, M., Börjesson, M., Bourdon, J., Ojeda Cabral, M., Chintakayala, P.K., Choudhury, C., Daly, A., Dekker, T., Drivyla, E., Fowkes, T. Hess, S., Heywood, C., Johnson, D., Laird, J., Mackie, P., Parkin, J., Sanders, S., Sheldon, R., Wardman, M., Worsley, T.: New appraisal values of travel time saving and reliability in Great Britain. Transportation 46(3), 583-621 (2019)

Berliner, R.M., Malokin, A., Circella, G., Mokhtarian, P.L.: Travel-based multitasking: modeling the propensity of northern californians to conduct activities while commuting. In: Paper Presented at 94th Annual Transportation Research Board Meeting, Washington DC (2015)

Bierlaire, M.: BIOGEME: a free package for the estimation of discrete choice models. In: Proceedings of the 3rd Swiss Transportation Research Conference, Ascona, Switzerland (2003)

Börjesson, M., Fosgerau, M., Algers, S.: On the income elasticity of the value of travel time. Transp. Res. A 46, 368-377 (2012)

Bruzelius, N.: The Value of Travel Time: Theory and Measurement. Croom Helm, London (1979)

DeSerpa, A.: A Theory of the economics of time. Econ. J. 81, 828-846 (1971)

Douglas, N., Jones, M.: Estimating the value of private travel time for new south wales. In: Paper Presented at 40th Australasian Transport Research Forum (2018)

Etezady, A., Mokhtarian, P.L., Circella, G., Malokin, A Investigating demographic and multitasking sources of systematic heterogeneity with respect to the impact of travel time on commute mode choice. In: Paper presented at 98th Annual Transportation Research Board Meeting, Washington DC (2019)

Ettema, D., Verschuren, L.: Multitasking a value of travel time savings. Transp. Res. Rec. 2010, 19-25 (2008) 
Ettema, D., Friman, M., Gärling, T., Olsson, L.E., Fujii, S.: How in-vehicle activities affect work commuters' satisfaction with public transport. J. Transp. Geogr. 24, 215-222 (2012)

Frei, C., Mahmassani, H.S., Frei, A.: Making time count: traveler activity engagement on urban transit. Transp. Res. A 76, 58-70 (2015)

Gripsrud, M., Hjorthol, R.: Working on the train: from 'dead time' to productive and vital time. Transportation 39, 941-956 (2012)

Gunn, H.F.: Spatial and temporal transferability of relationships between travel demand, trip cost and travel time. Transp. Res. E 37, 163-189 (2001)

ITF (2019) What is the value of saving travel time? ITF Roundtable Reports, No. 176, OECD Publishing, Paris

Hague Consulting Group, Accent Marketing and Research and Department for Environment, Transport and the Regions.: The Value of Travel Time on UK Roads. The Hague (1999)

Kenyon, S., Lyons, G.: Introducing multitasking to the study of travel and ICT: examining its extent and assessing its potential importance. Transp. Res. A 41, 161-175 (2007)

Keseru, I., Macharis, C.: Travel-based multitasking: review of the empirical evidence. Transp. Rev. 38(2), 162-183 (2018)

Kouwenhoven, M., de Jong, G.: Value of travel time as a function of comfort. J. Choice Model. 28, 97-107 (2018)

Lyons, G., Urry, J.: Travel time use in the information age. Transp. Res. Part A. Policy Pract. 39(2-3), 257-276 (2005)

Lyons, G., Jain, J., Holley, D.: The use of travel time by rail passengers in Great Britain. Transp. Res. A 41(1), 107-120 (2007)

Lyons, G., Jain, J., Weir, I.: Changing times-a decade of empirical insight into the experience of rail passengers in Great Britain. J. Transp. Geogr. 57, 94-104 (2016)

Leigh Fisher, Institute for Transport Studies University of Leeds, RAND Europe and SYSTRA.: Rail Demand Forecasting Extension. Prepared for Department for Transport (2016)

Lyons, G., Jain, J., Susilo, Y., Atkins, S.: Comparing rail passengers' travel time use in Great Britain between 2004 and 2010. Mobilities 8(4), 560-579 (2013)

Mackie, P., Worsley, T., Eliasson, J.: Transport appraisal revisited. Res. Transp. Econ. 47, 3-18 (2014)

Malokin, A., Circella, G., Mokhtarian, P.L.: How do activities conducted while commuting influence mode choice? Using revealed preference models to inform public transportation advantage and autonomous vehicle scenarios. Transp. Res. A 124, 82-114 (2019)

Malokin, A., Circella, G., Mokhtarian, P.L.: Do multitasking millennials value travel time differently? A revealed preference study of northern california commuters. In: Presented at 96th Annual Conference, Transportation Research Board, Washington DC (2017)

McIntosh, P.T., Quarmby, D.A. Generalised Costs and the Estimation of Movement Costs and Benefits in Transport. Mathematical Advisory Unit Note 179, Department for Transport. Also available in Highway Research Record 383 (1972) pp. 11-26. (1970)

Mokhtarian, P.L., Salomon, I.: How derived is the demand for travel? Some conceptual and measurement considerations. Transp. Res. A 35, 695-719 (2001)

Mokhtarian, P.L., Papon, F., Goulard, M., Diana, M.: What makes travel pleasant and/or tiring? An investigation based on the french national travel survey. Transportation 42(6), 1103-1128 (2015)

MVA Consultancy, Institute for Transport Studies University of Leeds, Transport Studies Unit University of Oxford.: The Value of Travel Time Savings. Policy Journals, Newbury (1987)

Rail Delivery Group.: Passenger Demand Forecasting Handbook, Version 6. London (2018)

Rasouli, S., Timmermans, H.: Judgments of travel experiences, activity envelopes, trip features and multitasking: a panel effects regression model specification. Transp. Res. A 63, 67-75 (2014)

Russell, M.L., Price, R., Signal, L., Stanley, J., Gerring, Z., Cumming, V.: What do passengers do during travel time? Structured observations on buses and trains. J. Public Transp. 14(3), 123-146 (2011)

Significance, VU University Amsterdam and John Bates: Value of time and reliability in passenger and freight transport in the netherlands. Rep. Minist. Infrastruct. Environ., The Hague (2012)

SYSTRA and Institute for Transport Studies (ITS) University of Leeds.: PDFH6 Update Methodology Report. Prepared for the Rail Delivery Group (2018)

Tang, J., Zhen, F., Cao, J., Mokhtarian, P.L.: How do passengers use travel time? a case study of ShanghaiNanjing high speed rail. Transportation 45, 451-477 (2018)

Tapley, N., Wardman, M., Gunn, H., Hyman, G.: Inter-temporal variations in values of time in Great Britain. In: Paper Presented at European Transport Conference, Noordwijkerhout, Netherlands (2007)

Wardman, M.: Review and meta-analysis of U.K. Time elasticities of travel demand. Transportation 39(3), 465-490 (2012). https://doi.org/10.1007/s11116-011-9369-2 
Wardman, M., Lyons, G.: The digital revolution and worthwhile use of travel time: implications for appraisal and forecasting. Transportation 43(3), 507-530 (2016)

Wardman, M., Batley, R., Laird, J., Mackie, P., Bates, J.: How should business travel time savings be valued? Econ. Transp. 4(4), 200-214 (2015)

Varghese, V., Jang, A.: Impact of ICT on multitasking during travel and the value of travel time savings: empirical evidence from Mumbai, India. Travel Behav. Soc. 12, 11-22 (2018)

van Hagen, M., de Bruyn, M., ten Elsen, E.: The power of a pleasant train journey. Transp. Res. Procedia 26, 177-186 (2017)

Van de Waerden, P., Timmermans, H., van Neerven, R.: Extent, nature and covariates of multitasking of rail passengers in an urban corridor: a Dutch case study. Transp. Res. Rec. J. Transp. Res. Board 2110, 106111 (2009)

Van der Waerden, P., Kemperman, A., van Hulle, R., Timmermans, H.: The influence of facilities for multitasking on individual's travel decisions in the context of work trips. In: Presented at the Transportation Research Board 89th Annual Meeting (2010)

Yosritzal, D.: An investigation into the role of technology in influencing the perception and value of travel time by rail. PhD Thesis, School of Civil Engineering and Geosciences, Newcastle University (2014)

Yosritzal, D., Adji, B.M., Dissanayake, D.: Indonesian experience on travel time use on-board of commuter rail services. Transp. Res. Procedia 25, 2705-2716 (2017)

Publisher's Note Springer Nature remains neutral with regard to jurisdictional claims in published maps and institutional affiliations.

Mark Wardman is an Independent Researcher and a Visiting Professor at the Institute for Transport Studies, University of Leeds. He has over 35 years' experience in the analysis of travel behaviour, with a particular interest in the valuation of travel time savings and rail demand forecasting using both Revealed Preference and Market Research based data. Mark has published extensively in these areas in leading international peer-reviewed journals and his research findings have had a considerable impact on appraisal guidance.

Phani Chintakayala is a Senior Research Fellow at Leeds University Business School and Leeds Institute for Data Analytics. His main area of research is consumer behaviour modelling. He has professional and academic cross-disciplinary research experience in modelling consumer behaviour in a wide range of sectors such as transport (Air, Rail, Road and Water), energy, insurance/banking, water, environment, marketing, health and food. He has contributed to several public facing schemes and policies.

Chris Heywood is a Director at Accent, a UK market research company. Chris has worked in market research for over thirty years and is a highly skilled manager of complex survey logistics, with experience of over 400 projects. He has particular interests in the development of innovative approaches to quantitative research and has pioneered several new techniques. Chris has extensive experience in the use of stated preference and other specialist research approaches applied in the transport sector.

\section{Affiliations}

\section{Mark Wardman $^{1}$ (D) Phani Chintakayala ${ }^{2} \cdot$ Chris Heywood $^{3}$}

Phani Chintakayala

P.Chintakayala@leeds.ac.uk

Chris Heywood

Chris.Heywood@accent-mr.com

1 Institute for Transport Studies, University of Leeds, Leeds LS2 9JT, UK

2 Consumer Data Research Centre and Leeds University Business School, University of Leeds, Leeds LS6 1AN, UK

3 Accent, Chiswick Gate, 598-608 Chiswick High Road, London W4 5RT, UK 